\title{
Identification of two nogo/rtn 4 genes and analysis of Nogo-A expression in Xenopus laevis
}

\author{
Michael Klinger, ${ }^{\mathrm{a}, 1}$ Heike Diekmann, ${ }^{\mathrm{a}, 1}$ Dietmar Heinz, ${ }^{\mathrm{a}}$ Cordula Hirsch, ${ }^{\mathrm{a}}$ \\ Sylvia Hannbeck von Hanwehr, ${ }^{\mathrm{a}}$ Barbara Petrausch, ${ }^{\mathrm{a}}$ Thomas Oertle, ${ }^{\mathrm{b}}$ Martin E. Schwab, \\ and Claudia A.O. Stuermer ${ }^{\mathrm{a}, *}$ \\ ${ }^{a}$ Department of Biology, University of Konstanz, 78457 Konstanz, Germany \\ ${ }^{\mathrm{b}}$ Department of Biology, ETH Zurich and Brain Research Institute, University of Zurich, 8057 Zurich, Switzerland
}

\begin{abstract}
Myelin-associated axon growth inhibitors such as Nogo-A/RTN4-A impair axon regeneration in the adult mammalian central nervous system (CNS). Here, we describe the cloning and expression of two independent Xenopus laevis rtn4 orthologs. As in mammals, alternative transcripts are generated both through differential splicing and promoter usage, giving rise to Xenopus nogo-A, -B, -C and to a new isoform, nogo-N/rtn4-N. Xenopus is therefore the 'lowest' vertebrate where Nogo-A was identified.

Xenopus Nogo-A/RTN4-A is predominantly expressed in the nervous system, whereas the other isoforms mainly occur in nonneuronal tissues. Nogo-A/RTN4-A specific antisera detect the protein in myelinated fiber tracts of the spinal cord, hindbrain, optic nerve, tectum opticum and in isolated oligodendrocytes. In addition, subpopulations of CNS neurons are Nogo-A/RTN4-A positive. This expression pattern is consistent with that observed for rat Nogo- $\mathrm{A}$ and suggests similar functions. Nogo-A in Xenopus myelin might therefore contribute to the failure of spinal cord regeneration in frogs a feature that may have evolved during the transition from fish to land vertebrates.
\end{abstract}

\section{Introduction}

In the adult mammalian and avian central nervous systems (CNS), regeneration of lesioned nerve fibers is prevented by inhibitory proteins that are particularly enriched in myelin and oligodendrocytes (Caroni and Schwab, 1988b), such as myelin associated glycoprotein (MAG) (McKerracher et al., 1994), oligo dendrocyte myelin glycoprotein (OMgp) (Wang et al., 2002a) and Nogo/RTN4 (Chen et al., 2000; GrandPré et al., 2000; Prinjha et al., 2000). Earlier functional studies indicated the presence of

\footnotetext{
* Corresponding author. Fax: +49-7531-88 3894.

E-mail address: Claudia.Stuermer@uni-konstanz.de (C.A.O. Stuermer).

${ }^{1}$ Both authors contributed equally.
}

related neurite growth inhibitors, in particular the IN 1 antigen, in oligodendrocytes/CNS myelin of Xenopus (Lang et al., 1995). The IN 1 antibody has originally been raised against a $250 \mathrm{kDa}$ myelin fraction (Caroni and Schwab, 1988a), and based on its neutralizing activity the bovine Nogo A ortholog (bNI220) has been purified (Spillmann et al., 1998).

Nogo/RTN4 is a member of the reticulon (RTN) family of proteins (Chen et al., 2000; GrandPré et al., 2000; Prinjha et al., 2000). These proteins share a conserved 188 amino acid (aa) long C terminal reticulon homology domain (RHD) (Oertle et al., 2003b). The two hydrophobic stretches within the RHD could serve as transmembrane domains for their insertion in endoplasmic reticulum (ER) and plasma membranes (Oertle et al., 2003c; van de Velde et al., 1994). Outside the RHD domain, Nogo/RTN4 and the other three RTN proteins (RTN1 3) have no obvious sequence similarities.

In mammals, the nogo/rtn 4 gene gives rise to different isoforms both through alternative splicing and alternative promoter usage with the three major transcripts known as nogo A, nogo B and nogo C (Oertle et al., 2003a). The largest isoform, Nogo A/RTN4 $\mathrm{A}$, has been described as a potent neurite growth inhibitor of CNS myelin with two inhibitory sites. A stretch in the Nogo A specific region (NiG $\Delta 20)$ is strongly inhibitory for neurite outgrowth and cell spreading in vitro (Oertle et al., 2003d). In addition, the loop region between the two $\mathrm{C}$ terminal hydrophobic domains of the RHD (called Nogo 66) has been shown to induce collapse of neuronal growth cones in vitro (GrandPré et al., 2000).

The RTN proteins are evolutionary conserved in eukaryotes (Oertle et al., 2003b), and therefore Nogo A homologs may exist and impair CNS axon regeneration in amphibians. In frogs, CNS axons fail to regenerate in the spinal cord after metamorphosis (Beattie et al., 1990; Forehand and Farel, 1982). The inability of regeneration correlates with the nonpermissive properties of spinal cord myelin and oligodendrocytes in cocultures with axons, indicating the expression of inhibitory proteins in this region (Lang and Stuermer, 1996; Lang et al., 1995). CNS myelin and oligoden drocytes from the optic nerve and tectum, where amphibian axons do regenerate, were not inhibitory to growing axons in vitro (Lang et al., 1995). Reasons may lie in regional differences concerning 

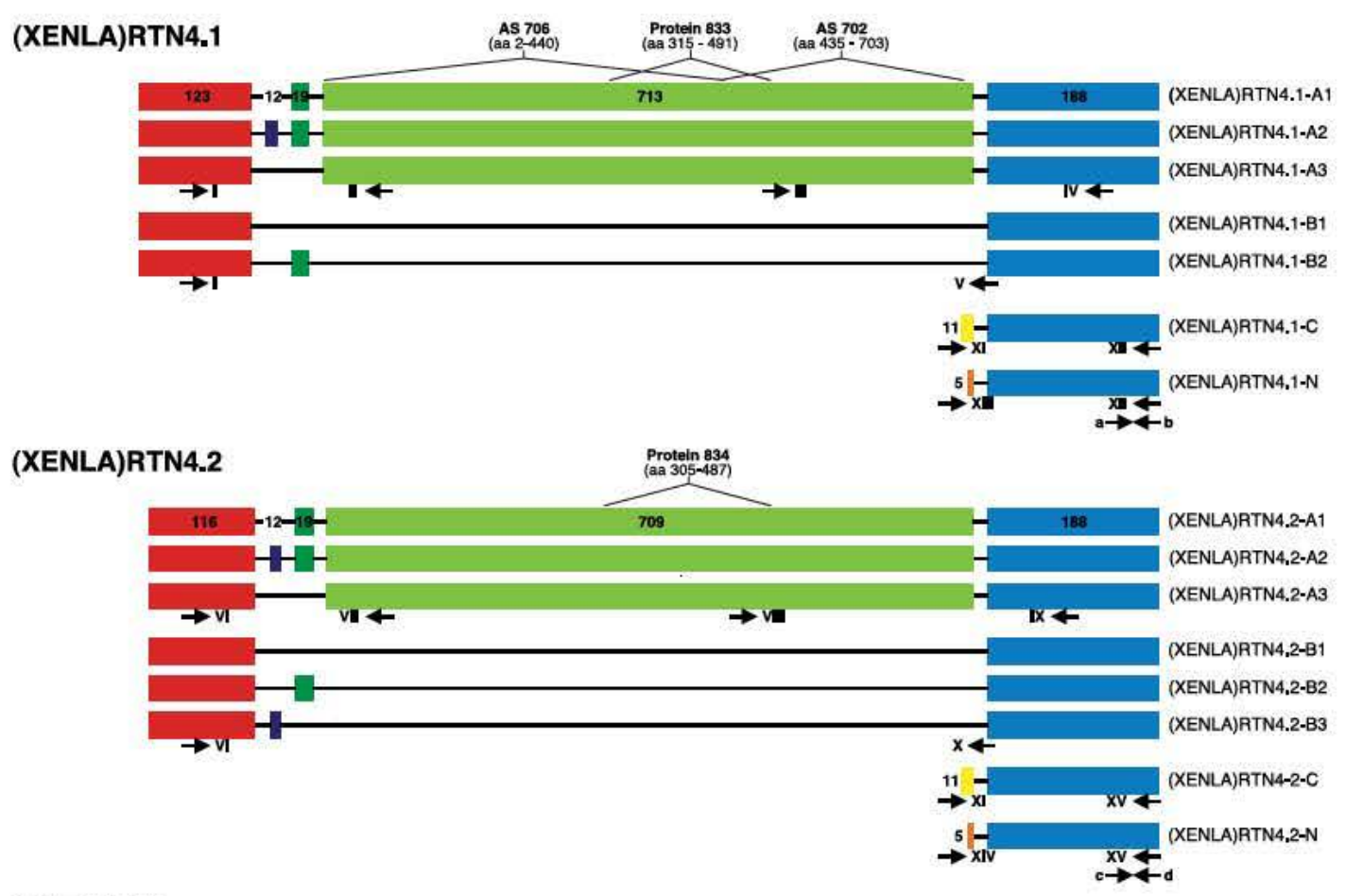

(RAT)RTN4

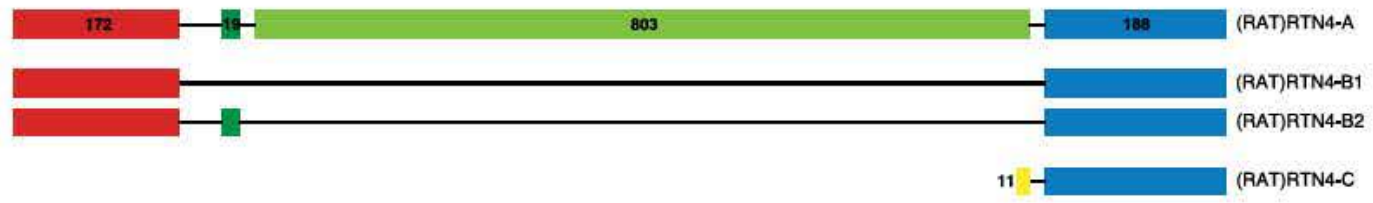

Fig. 1. Schematic representation of Xenopus nogo/rtn4 in comparison to rat nogo/rtn4 transcripts. Two nogo/rtn4 genes were identified in X. laevis and the different transcripts were named according to the nomenclature guidelines for reticulon genes ((XENLA)rtn4.1, (XENLA)rtn4.2; see Experimental methods). Their overall structures correspond to mammalian rtn4. Nogo-A/rtn4-A consists of an N-terminal A/B-specific region (red), a central A-specific region (light green) and the RHD (blue). In the B-isoforms, the A-specific region is missing. For both the A-and B-isoforms, multiple minor splice variants exist due to the alternative usage of two (Xenopus) or one (mammals) small exons (dark blue and dark green). RTN4-C (yellow) and RTN4-N (orange) are transcribed from alternative promoters, but the RHD is the same as for the -A and -B isoforms. The amino acid length of the respective regions is depicted by Arabic numerals. Localizations of primers are indicated by arrows and Roman numerals (RT-PCR) or lower case letters (genomic PCR). The range of recombinant proteins used for the generation of polyclonal antisera against Nogo-A is outlined with brackets. AS, polyclonal antiserum.

the expression of myelin inhibitors or their subcellular localization, for example, surface exposure in myelin membranes or retention in the ER.

We used conserved sequence motifs of mammalian nogo A to search for Xenopus nogo/rtn 4 homologs. Various transcripts corresponding to the three major isoforms $\mathrm{rtn} 4 \mathrm{~A}, \mathrm{~B}$ and $\mathrm{C}$ were

Fig. 2. PCR analysis of Xenopus rtn 4 introns. The existence of two independent nogo/rtn 4 genes was proven by PCR analysis of intron sizes. Specificity of the used primer pairs for one of the two $r$ tn 4 genes (primers a $+\mathrm{b}$ for $\mathrm{rtn} 4.1$ and primers $\mathrm{c}+\mathrm{d}$ for $\mathrm{rtn} 4.2$; see Fig. 1) was verified by PCR on cloned plasmid DNA ( + control; - control). (A) Primers $\mathrm{a}+\mathrm{b}$ amplified the expected PCR product of 110 bp only on $r$ tn 4.1 (lane 4) but not on $r$ tn4.2 (lane 3) plasmid DNA. On two different genomic DNA templates (prepared from either wild-type or albino $X$. laevis), the amplicon was 678 bp (lanes 1 and 2). (B) Primers $\mathrm{c}+\mathrm{d}$ were specific for $\mathrm{rtn} 4.2$ (lane 3 ) and no amplification was achieved on rtn4.1-negative control plasmid (lane 4). The PCR product on genomic DNA templates was 490 bp (lanes 1 and 2). wt, wild-type.
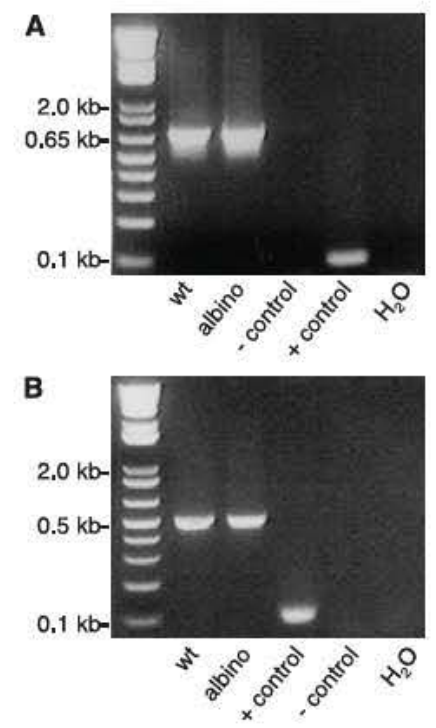
identified. In contrast to mammals, we found an additional short, so far unknown, isoform termed $\mathrm{rtn} 4 \mathrm{~N}$. The nogo/rtn 4 gene under went a Xenopus specific duplication, which would allow inde pendent transcriptional regulation of the two nogo gene copies. Tissue specific transcription of the different nogo/rtn 4 cDNAs was analysed by RT PCR. Nogo A/RTN4 A protein expression was detected with Xenopus Nogo A/RTN4 A specific antibodies in oligodendrocytes and major myelinated fiber tracts. Its distribution is comparable to the Nogo A expression in mammals and because Nogo A forms are not found in zebrafish (Klinger et al., 2002; Oertle et al., 2003b) indicates that the evolution of this neurite growth inhibitor has occurred in land vertebrates.

\section{Results}

\section{Identification and characterization of Xenopus laevis rtn 4}

We have cloned full length cDNAs of altogether 15 different $X$. laevis (XENLA) nogo/rtn 4 transcripts by degenerate PCR, RACE and RT PCR. Fig. 1 gives a schematic overview of these transcripts and illustrates the relationship between Xenopus and rat $\mathrm{rtn} 4$ isoforms. Based on RHDs, which form the $\mathrm{C}$ terminal part of all RTN4 proteins, we were able to assign the sequences to two groups (rtn4.1, rtn4.2), indicating a $X$. laevis specific gene duplication (see below). As in human, rat and mouse (Chen et al., 2000; GrandPré et al., 2000; Prinjha et al., 2000), the three major transcripts rtn4 A, $\mathrm{B}$ and $\mathrm{C}$ also exist for both Xenopus genes. Small, alternatively spliced exons lead to multiple mRNA variants of the A and B isoforms (Figs. 1 and 3). Unexpectedly, we identified an additional, so far unknown, rtn 4 isoform with a short $\mathrm{N}$ terminus of 5 aa, which we named (XENLA)rtn4 $\mathrm{N}$.

The full length (XENLA)rtn4.1 A1/4.2 Al sequences consist of 4024/3898 base pairs (bp), with open reading frames (ORFs) coding for 1043/1032 aa, respectively. Compared to rat Nogo A, the coding regions are 120/131 aa shorter based on length differ ences both in the Nogo A/B specific regions (49/56 aa shorter) and the Nogo A specific regions (71/75 aa shorter). The RHDs are exactly as long as in the rat (188 aa; Fig. 1). At their C termini, a dilysine ER retention motif (KRKAE) is present. Xenopus rtn4.1 A and $\mathrm{rtn} 4.2 \mathrm{~A}$ each have one major ( $\mathrm{rtn} 4 \mathrm{~A} 1$ ) and two minor splice variants arising from the alternative usage of two small exons of 36 bp (12 aa) and 57 bp (19 aa; Fig. 1). These exons are either both present ( $r$ n $4 \mathrm{~A} 2$ ), both absent (rtn $4 \mathrm{~A} 3$ ) or individually used ( $\mathrm{rtn} 4$ A1). The 36 bp exon is unique for the Xenopus rtn 4 genes and was not identified in mammals (Oertle et al., 2003a). The full length Nogo A1/RTN4 Al proteins and the respective rat ortholog share an overall identity of $34 \%$, with the highest sequence conservation in the RHD. Xenopus RTN4.1 A1 and RTN4.2 A1 are $78.3 \%$ identical and are therefore more closely related to each other than to any other mammalian Nogo A/RTN4 A. Rtn4.1 B and rtn4.2 B are alternative splice forms of $\mathrm{rtn} 4.1 \mathrm{~A}$ and $\mathrm{rtn} 4.2 \mathrm{~A}$, respectively, sharing the respective $\mathrm{N}$ terminal $\mathrm{A} / \mathrm{B}$ specific regions with the start codons, the RHDs and the untranslated regions (UTRs), but lacking the A specific central exons (Fig. 1). The sequences surrounding the putative start methionines of $\mathrm{rtn} 4.1 \mathrm{~A} / \mathrm{B}$ and $\mathrm{rtn} 4.2 \mathrm{~A} / \mathrm{B}$ (cccGccATGG/gecGcaATGG) comply with the consen sus motif for initiation of translation (gccAccATGG) that particu larly requires a $\mathrm{G}$ residue following the ATG and a purine at position 3 (Kozak, 1996). Although there are no upstream stop codons in the cloned $5^{\prime}$ UTRs (110/118 bp), the consensus motifs

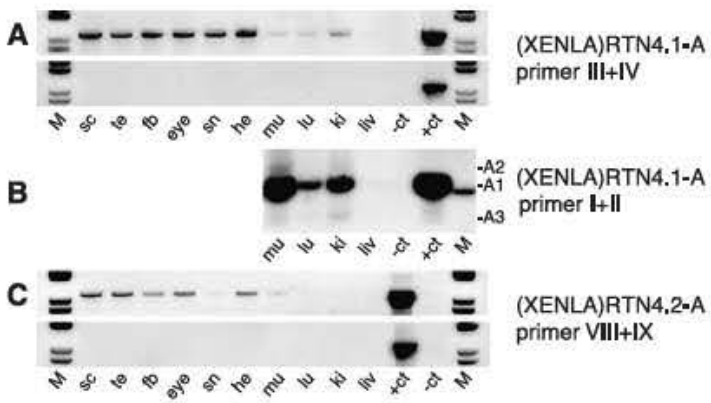

D

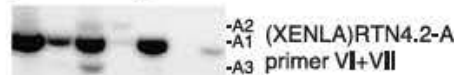
है?
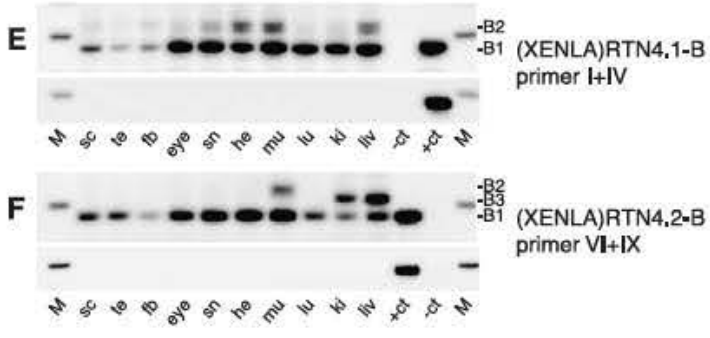

(XENLA)RTN4.2-B primer $\mathrm{V} \mathbf{1}+\mathrm{IX}$

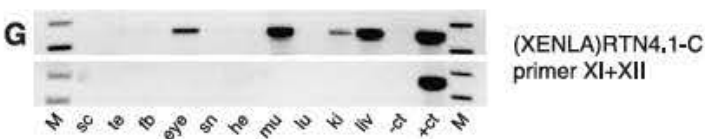

H

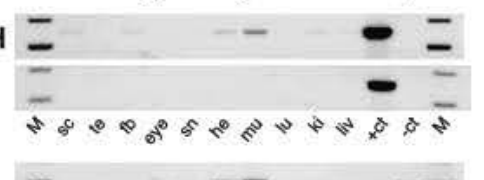

(XENLA)RTN4,2-C primer $\mathrm{XI}+\mathrm{XV}$

I

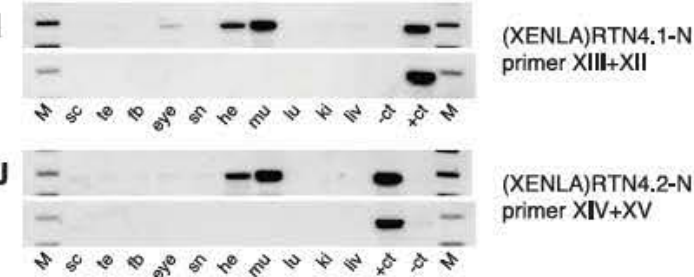

$\mathrm{K}=---\cdots-\cdots-\cdots=$

(XENLA)clathrin

Fig. 3. RT-PCR analysis of Xenopus $\mathrm{rtn} 4 \mathrm{mRNA}$ expression. Transcripts of rtn4-A, - B, - C and - $\mathrm{N}$ were detected in various Xenopus tissues (upper row of panels A J). Lanes + ct and - ct are control PCRs on plasmid DNAs to prove specificity of the primers for $\mathrm{rtn} 4.1$ and $\mathrm{rtn} 4.2$, respectively. A 'zero reverse transcriptase' negative control was conducted with each primer pair to show that no bands were amplified due to genomic DNA contamination of the templates (lower row of panels A J). (A) Amplification of rtn4.1-A. (B) Detection of rtn4.1-A splice variants in nonneuronal tissues. (C) Amplification of $\mathrm{rn} 4.2-\mathrm{A}$. (D) Detection of $\mathrm{rn} 4.2-\mathrm{A}$ splice variants in nonneuronal tissues. (E) Analysis of rtn4.1-B splice variants. (F) Analysis of $r$ 4n4.2-B splice variants. (G) Amplification of $\mathrm{rtn} 4.1-\mathrm{C}$. (H) Amplification of $\mathrm{rtn} 4.2-\mathrm{C}$. (I) Expression of $\mathrm{rtn} 4.1-\mathrm{N}$. (J) Expression of $\mathrm{rtn} 4.2-\mathrm{N}$. (K) RT-PCR with clathrin-specific primers served as positive control to ensure that equal amounts of cDNA template were used in each reaction. $\mathrm{H}_{2} \mathrm{O}$ was a 'no template' control. sc, spinal cord; te, tectum opticum; fb, forebrain; sn, sciatic nerve; he, heart; mu, muscle; lu, lung; ki, kidney; liv, liver; + ct, positive control; - ct, negative control. 
Table 1

Comparison of semiquantitative expression levels of the major RTN4 isoforms in Xenopus and mammals (human, rat)

\begin{tabular}{|c|c|c|c|c|c|c|c|}
\hline & \multicolumn{2}{|l|}{ RTN4-AI } & \multicolumn{2}{|l|}{ RTN4-B1 } & \multicolumn{2}{|l|}{ RTN-C } & \multirow{2}{*}{$\frac{\text { RTN4-N }}{\text { Xenopus }}$} \\
\hline & Xenopus & Human or rat & Xenopus & Human or rat & Xenopus & Human or rat & \\
\hline Spinal cord & H & H & + & + & - & \pm & - \\
\hline Tectum ${ }^{a}$ & H & ++ & + & + & - & \pm & - \\
\hline Forebrain & H & H & + & + & - & \pm & - \\
\hline Eye & ++ & ++ & + & + & $+(4.1)-(4.2)$ & + & $+(4.1)-(4.2)$ \\
\hline Sciatic Nerve & $++(4.1)+(4.2)$ & \pm & H & H & - & - & - \\
\hline Heart & ++ & + & + & + & $-(4.1)+(4.2)$ &,$-+^{b}$ & ++ \\
\hline Muscle & \pm &,$+-^{\mathrm{c}}$ & + & + & $++(4.1)+(4.2)$ & H & + \\
\hline Lung & \pm & - & $++(4.1)+(4.2)$ & + & - & - & - \\
\hline Kidney & \pm & - & $++(4.1)+(4.2)$ & + & $+(4.1)-(4.2)$ & + & - \\
\hline Liver & - & - & $+(4.1)+(4.2)$ & - & $+(4.1)-(4.2)$ &,$+-^{b}$ & - \\
\hline
\end{tabular}

Data for Xenopus are based on RT-PCRs shown in Fig. 3 and Western blots (Fig. 4B) and apply to both genes if not indicated in parentheses. Data for human and rat are taken from tables in (Oertle and Schwab, 2003; Hunt et al., 2002a).

++ , Strong expression; + , clear expression; \pm , weak expression; - , no detectable expression.

a Tectum opticum in Xenopus; thalamus, amygdala, habenular nuclei in mammals.

${ }^{\mathrm{b}}$ Conflicting data.

${ }^{\mathrm{c}}$ Positive in immature skeletal muscle, negative in adult muscle.

and the absence of alternative start codons suggest that the identified methionines are the $\mathrm{N}$ termini of the respective (XEN LA)RTN4 A and B proteins. In the $3^{\prime}$ UTRs ( $\left.782 / 681 \mathrm{bp}\right)$, poly adenylation signals (AATAAA) were identified 20/27 bp upstream of the poly A tails, proving that the entire $3^{\prime}$ UTRs were cloned for both $r$ tn 4 genes.

As in mammals (Oertle et al., 2003a), (XENLA)rtn4.1 C and (XENLA)rtn $4.2 \mathrm{C}$ are driven by alternative promoters. The $\mathrm{C}$ specific exons each code for 11 aa that are $91 \%$ identical to each other and share $36 \%$ sequence identity with rat exon 1C (Oertle et al., 2003a). The sequences surrounding the putative start methio nines are tcaGaaATGG and tcaGagATGG.

Interestingly, we identified a further isoform, $\mathrm{rtn} 4 \mathrm{~N}$, for both Xenopus genes that has not been found in any mammalian species. The transcription of (XENLA)rtn $4 \mathrm{~N}$ is probably driven from an alternative promoter. The lengths of the $\mathrm{N}$ specific exons are $16 \mathrm{bp}$ ( 5 aa) and the encoded aa are $100 \%$ identical. An orthologous isoform with $80 \%$ sequence identity has also been identified in zebrafish (Klinger et al., 2002; Oertle et al., 2003b).

All sequences were deposited in GenBank (GenBank accession numbers, AY316183 AY316197).

\section{Existence of two Xenopus rtn 4 genes}

Two Xenopus $\mathrm{rtn} 4$ A clones with a sequence divergence of $13 \%$ at the cDNA level were initially identified by PCR with degenerate primers (for details see Experimental methods). To test whether these two forms are alleles or independent Xenopus rtn 4 genes, the length and sequence identity of RHD introns were analysed (Fig. 2). Because rtn $4 \mathrm{~A}, \mathrm{~B}, \mathrm{C}$ and $\mathrm{N}$ are isoforms transcribed from the same gene and share the RHD, evidence for two RHDs is sufficient to prove the existence of two independent $r$ tn 4 genes. Based on the known intron/exon structure of the human and mouse orthologs (Oertle et al., 2003a), PCR was performed on genomic DNA to amplify intron IV sequences (between the 4th and 5th exon of the RHD; for primer sequences and positions, see Supplementary Table 1B and Fig. 1). Rtn4.1 specific primers amplified the expected product of $110 \mathrm{bp}$ on $\mathrm{rtn} 4.1$ positive control plasmid DNA but not on rtn4.2 (negative control). PCR on two different genomic DNA templates (wild type (wt) and albino) resulted in an amplicon of 678 bp (Fig. 2A). In contrast, rtn4.2 specific primers amplified the expected product on $\mathrm{rtn} 4.2$ positive control plasmid DNA, but not on an rtn 4.1 negative control. On genomic DNA, the amplicon was 490 bp (Fig. 2B). Thus, this intron of $r t n 4.1$ is $188 \mathrm{bp}$ longer. Its sequence differs by $36 \%$ from

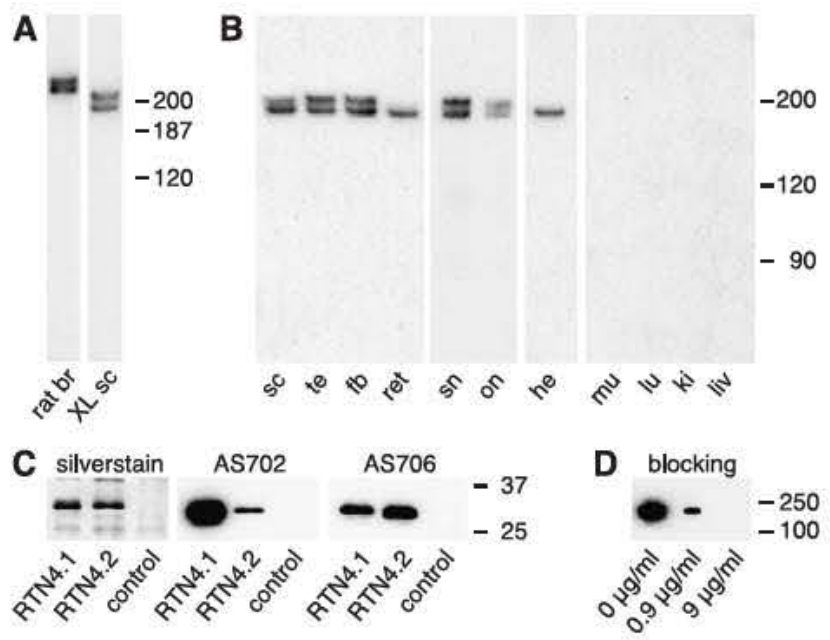

Fig. 4. Westem blot analysis of Xenopus Nogo-A/RTN4-A protein expression. (A) Xenopus Nogo-A/RTN4-A proteins detected with AS702 in the spinal cord homogenate (XL sc) exhibit a lower molecular weight than the homologous rat protein detected with AS472 (Chen et al., 2000) in the brain homogenate (rat br). Rat and Xenopus Nogo-A proteins migrate aberrantly slow in SDS-PAGE due to their acidic nature. (B) Expression of Nogo-A/RTN4-A proteins in different Xenopus tissues was analysed with the Nogo-A specific AS702. sc, spinal cord; te, tectum opticum; fb, forebrain; ret, retina; sn, sciatic nerve; on, optic nerve; he, heart; mu, muscle; lu, lung; ki, kidney; liv, liver. (C) A part of RTN4.1-A (protein 833, see Fig. 1), RTN4.2-A (protein 834) and an unrelated control protein were recombinantly expressed (left panel, silver staining) and Westerm blots were probed with AS702 (middle panel) and AS706 (right panel). AS702 as well as AS706 recognized both RTN4.1-A and RTN4.2-A. (D) Tectum opticum homogenate was probed with AS706 and a concentration-dependent signal reduction was achieved by blocking the antiserum with increasing amounts of recombinantly expressed 706 protein $(0,0.9,9 \mu \mathrm{g} / \mathrm{ml})$. AS, polyclonal antiserum. 
its $r$ tn 4.2 counterpart. Similar results were obtained by the analysis of other introns and of the $3^{\prime}$ UTRs (data not shown), proving the existence of two independent rtn 4 genes in $X$. laevis.

Whether the two rtn 4 genes result from the $X$. laevis specific tetraploidization was evaluated by computing the rates of syno nymous (silent) and nonsynonymous (aa altering) nucleotide substitutions ( $d_{\mathrm{S}}$ and $d_{\mathrm{N}}$; Supplementary Table 2 ). Assuming that silent mutations accumulate at approximately constant rates, the elapsed time since the duplication is proportional to $d_{\mathrm{S}}$ of the two Xenopus rtn4 A transcripts and can be calculated by comparison to the corresponding rates of the human and rat cDNAs (Hughes and Hughes, 1993). Consistent with an rtn4 gene duplication more recent than the divergence of rodents and primates approx imately 80100 million years ago (MYA) (Li et al., 1990), $d_{\mathrm{S}}$ of the two Xenopus $\mathrm{rtn} 4$ A transcripts $(26.6 \pm 2.2$ substitutions/100 sites) was lower than the mammalian $d_{\mathrm{S}}(44.3 \pm 3$ substitutions/ 100 sites). This rate is comparable to $d_{\mathrm{S}}$ of other duplicated Xenopus genes (Hughes and Hughes, 1993), suggesting that the rtn4 gene duplication occurred during the tetraploidization event approximately 30 MYA. Unexpectedly, the rate of aa altering mutations $\left(d_{\mathrm{N}}\right)$ of the $\mathrm{rtn} 4$ A transcripts $(10.3 \pm 0.7$ substitutions/ 100 sites) was explicitly higher than for other duplicated Xenopus genes, almost reaching the $d_{\mathrm{N}}$ of the rat and human rtn 4 orthologs $(11.9 \pm 0.7$ substitutions $/ 100$ sites $)$. However, neither of the two copies evolved significantly faster than the other at nonsynon ymous sites ( $59.6 \pm 2.5$ compared to $58.4 \pm 2.6)$, as was shown by separate comparison of each Xenopus gene to the human rtn 4 ortholog.

This result indicates that both Xenopus rtn 4 genes evolved equally fast and that neither gene copy is redundant and therefore free to accumulate mutations without constraint.

\section{RT PCR analysis of Xenopus rtn 4 mRNA expression}

Transcription of rtn 4 in different tissues of adult $X$. laevis was analysed by RT PCR (for an overview see Table 1). Using primers that do not discriminate among the three different $r$ tn $4.1 \mathrm{~A}$ splice variants (primers III + IV, see Fig. 1), expression was predomi nantly observed in CNS tissues, that is, spinal cord, tectum opticum, forebrain and eye, but also in sciatic nerve and heart (Fig. 3A). Faint bands indicating low expression levels were visible in the muscle, lung and kidney. Rtn4.2 A transcripts, in comparison, were expressed in a similar pattern at an overall lower level, especially in sciatic nerve, and under these PCR conditions not detectable in the lung, kidney and liver (Fig. 3C, primers VIII + IX). To distinguish among the three splice products of rtn 4 A ( A1, A2 and A3), we applied sensitive RT PCR (see Experimental methods). Amplification of the region that could vary in length due to the alternative usage of the two 36 and 57 bp exons (primer I + II for rtn4.1 A and VI + VII for rtn4.2 A; Fig. 1) detected only the major splice variant ( A1; with the 57 bp exon and without the 36 bp exon) in all neuronal tissues and heart (data not shown). In nonneuronal tissues, additional, so far undetected expression and alternative splice products were revealed. For rtn4.1, the major transcript ( A1) was expressed in the muscle, lung and kidney, whereas rtn4.1 A2 (containing both exons) was present only in muscle and rtn4.1 A3 (both exons missing) only in kidney (Fig. 3B). Using this more sensitive PCR for $\mathrm{rtn} 4.2$, we unexpectedly found A1 mRNA transcripts in all nonneuronal tissues (Fig. 3D). Rtn4.2 A2 was detectable in the kidney and liver while rtn4.2 A3 expression was restricted to the kidney.
Transcripts for both rtn4 B1 forms (the main -B splice variant) were verified in all tissues analysed (Figs. $3 \mathrm{E}$ and F), although expression levels were low in the spinal cord, tectum opticum, forebrain (rtn4.1 and 2) and lung (rtn4.2). Hence, transcription of the $\mathrm{rtn} 4 \mathrm{~B}$ forms predominantly in nonneuronal tissues is almost complementary to the $\operatorname{rtn} 4$ A expression. For rtn $4.1 \mathrm{~B}$, one addi tional splice form appeared in all tissues (rtn4.1 B2; Fig. 3E). In contrast, tissue specific alternative splicing was observed for $\mathrm{rtn} 4.2$, with $\mathrm{rtn} 4.2 \mathrm{~B} 2$ occurring only in the muscle and $\mathrm{rtn} 4.2$ $\mathrm{B} 3$ in the kidney and liver (Fig. 3F).

Rtn4.1 C mRNA was detectable in the eye, muscle, kidney and liver (Fig. 3G). In comparison, $\mathrm{rtn} 4.2 \mathrm{C}$ transcription occurred at a much lower level with clearly detectable expression only in the heart and muscle (Fig. 3H). Similarly, the rtn $4.1 \mathrm{~N}$ and rtn4.2 N isoforms were both mainly expressed in the heart and muscle (Figs. 3I and J).

Taken together, these RT PCR results indicate that the various transcripts of each Xenopus rtn 4 gene are differentially expressed. While the major $\mathrm{A}, \mathrm{B}$ and $\mathrm{N}$ isoforms have a comparable expression pattern for both Xenopus rtn 4 genes, the distribution of the $\mathrm{C}$ form as well as of minor $\mathrm{A}$ and $\mathrm{B}$ splice variants differs between the two genes.

\section{Distribution of Xenopus Nogo A/RTN4 A protein}

Selected A specific regions of RTN4.1 were recombinantly expressed (see Experimental methods) and used for the generation of polyclonal antisera AS702 and AS706 (Fig. 1). To show whether the obtained antisera are specific for RTN4.1 or recognize both Xenopus RTN4 A proteins, a part of RTN4.1 A (protein 833, see Fig. 1), RTN4.2 A (protein 834) and an unrelated control protein were recombinantly expressed (Fig. 4C, left panel) and Western blots were probed with AS702 (Fig. 4C, middle panel) and AS706 (Fig. 4C, right panel). Both antisera recognized RTN4.1 A as well as RTN4.2 A proteins (Fig. 4C) and did not discriminate between the RTN4 A proteins of the two genes.

In Xenopus spinal cord homogenate, AS702 (Fig. 4A) and AS706 (data not shown) recognized two bands of approximately $200 \mathrm{kDa}$. Because the calculated molecular weights $(113.99 / 113.59$ $\mathrm{kDa})$ and $\mathrm{pIs}(4.4 / 4.5)$ of the two Nogo A1/RTN4 A1 proteins are almost identical, the second band most probably represents a different posttranslational modification of one or both proteins. In comparison to rat Nogo A (about $220 \mathrm{kDa}$; Fig. 4A), the Xenopus proteins migrated faster in SDS PAGE, which is consis tent with the $13 \mathrm{kDa}$ difference in the calculated molecular weights. Western blot studies on Xenopus tissues revealed that Nogo A/RTN4 A expression was mainly restricted to the nervous system, which is in accordance with the RT PCR analysis. In addition to spinal cord, two protein forms were detected in the tectum opticum, forebrain, sciatic and optic nerves, but only one was found in the retina and heart (Fig. 4B). No Nogo A/RTN4 A protein was observed in nonneuronal tissues (i.e., muscle, lung, kidney or liver). Specificity of polyclonal AS706 for Xenopus RNT4 A was shown on Western blots of the tectum opticum homogenate. Concentration dependent signal reduction was achieved by blocking the antiserum with increasing amounts of recombinantly expressed 706 protein (Fig. 4D). Adding $0.9 \mu \mathrm{g} / \mathrm{ml}$ 706 protein to the antibody solution significantly reduced the signal whereas a concentration of $9 \mu \mathrm{g} / \mathrm{ml}$ led to a complete loss.

Immunostaining on cross sections of adult Xenopus spinal cord revealed Nogo A/RTN4 A expression in myelinated tracts of the 

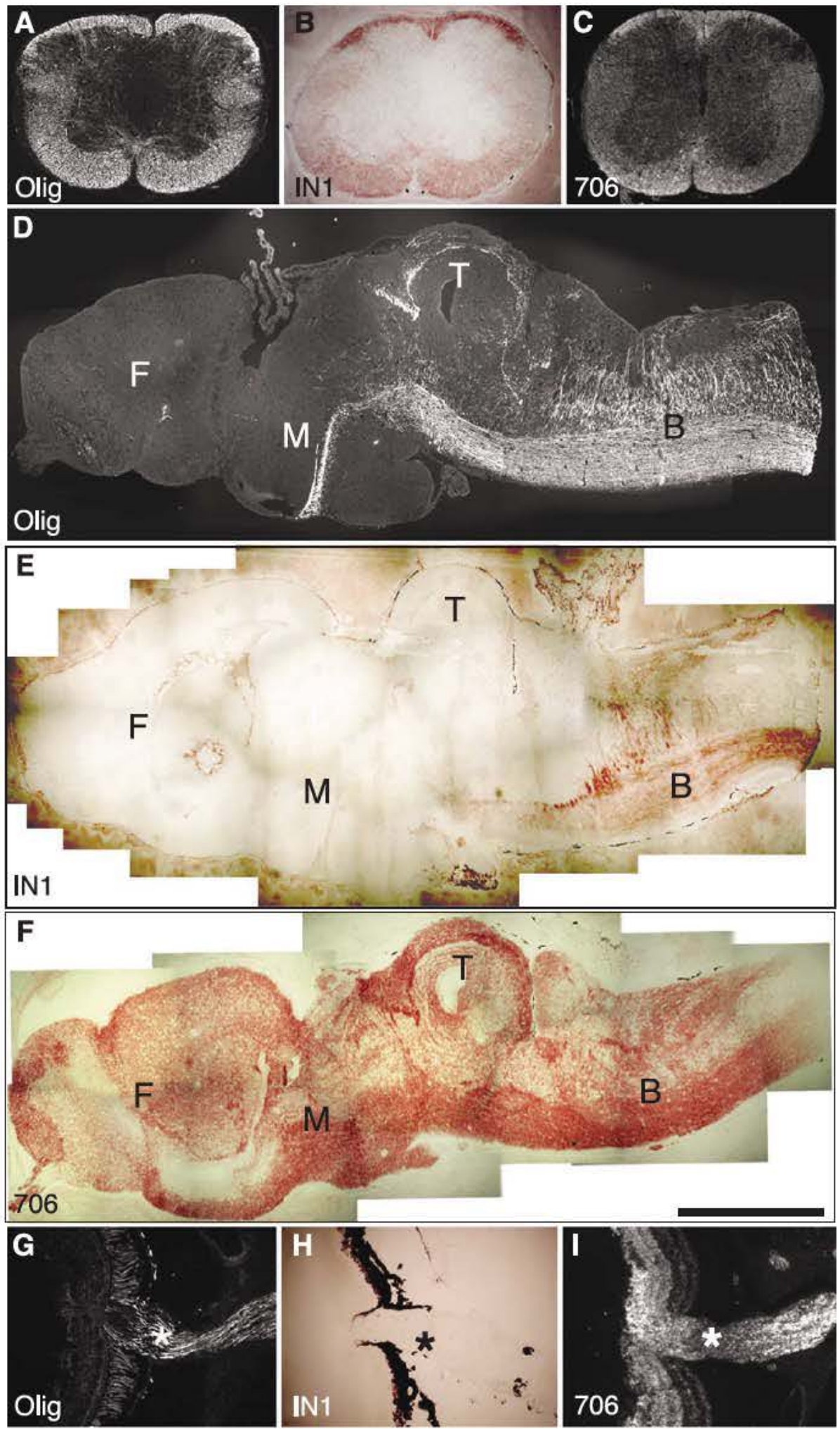

Fig. 5. Immunolocalisation of Nogo-A/RTN4-A protein in the Xenopus CNS. Sections of Xenopus spinal cord (A C; cross), brain (D F, sagittal) and optic nerve (G I, longitudinal) were immunostained with AS706 (C, F, I). The expression of Nogo-A/RTN4-A protein was compared to the distribution of the oligodendrocyte-specific marker Olig (A, D, G) and the mAb IN-1 staining (B, E, H). Nogo-A is detected in myelinated fiber tracts of the spinal cord (C), brain (F) and optic nerve (I). AS706 also labels unmyelinated regions in the forebrain or midbrain (F). B, brainstem; F, forebrain; M, midbrain; T, tectum opticum; *, optic nerve. The staining of photoreceptors (G) is unspecific. Scale bar is $500 \mu \mathrm{m}$ in A C, $1000 \mu \mathrm{m}$ in D F and $200 \mu \mathrm{m}$ in G I. 

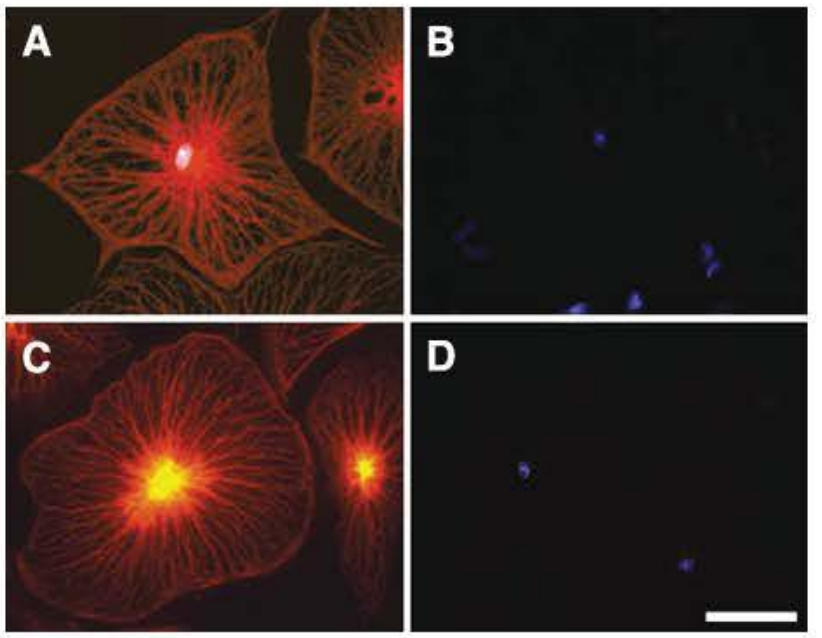

Fig. 6. Detection of Nogo-A/RTN4-A protein in Xenopus oligodendrocytes. Cultured oligodendrocytes isolated from Xenopus spinal cord (A, B) or optic tectum (C, D) were stained with the Nogo-A/RTN4-A specific AS706 (red) and the nuclear stain DAPI (blue). Nogo-A/RTN4-A is predominantly detected in intracellular compartments after permeabilisation (A, C). This staining is blocked by preincubation of AS706 with the protein used for antibody generation (B, D). Scale bar is $50 \mu \mathrm{m}$. white matter (Fig. 5C), as was observed for the rat Nogo A protein (Chen et al., 2000). The staining pattern was comparable to the distribution of the oligodendrocyte markers Olig (Fig. 5A), O4 (data not shown) and of the IN 1 antibody (Fig. 5B). On sagittal sections of Xenopus brain, Olig labeled myelinated longitudinal and transverse fiber tracts in the ventral part of the brainstem (Fig. 5D). Corresponding fiber tracts were also detected, though weaker, with the IN 1 antibody (Fig. 5E). In addition, Olig brightly stained a single layer in the optic tectum that was not revealed with IN 1. Nogo A/RTN4 A expression detected after Clark's fixation with AS706 (Fig. 5F) and AS702 (data not shown) encompassed myelinated as well as cellular regions of the Xenopus brain. Myelinated fiber tracts in the brainstem and in the optic tectum were stained. In addition, extensive labeling of nonmyelinated areas that has also been demonstrated for rat Nogo A (Huber et al., 2002) was observed especially in the forebrain region (Fig. 5F).

Myelin in the adult optic nerve was detected with the Olig marker (Fig. 5G) and corresponded to staining pattern of AS706 (Fig. 5I) and AS702 (data not shown), indicating Nogo A/RTN4 A expression in the optic nerve and tract. The IN 1 antibody, however, failed to label the Xenopus optic nerve (Fig. 5H), which is consistent with our earlier results (Lang et al., 1995).

Localization of Nogo A/RTN4 A protein in Xenopus CNS myelin was consolidated by immunostaining of cultured oligoden
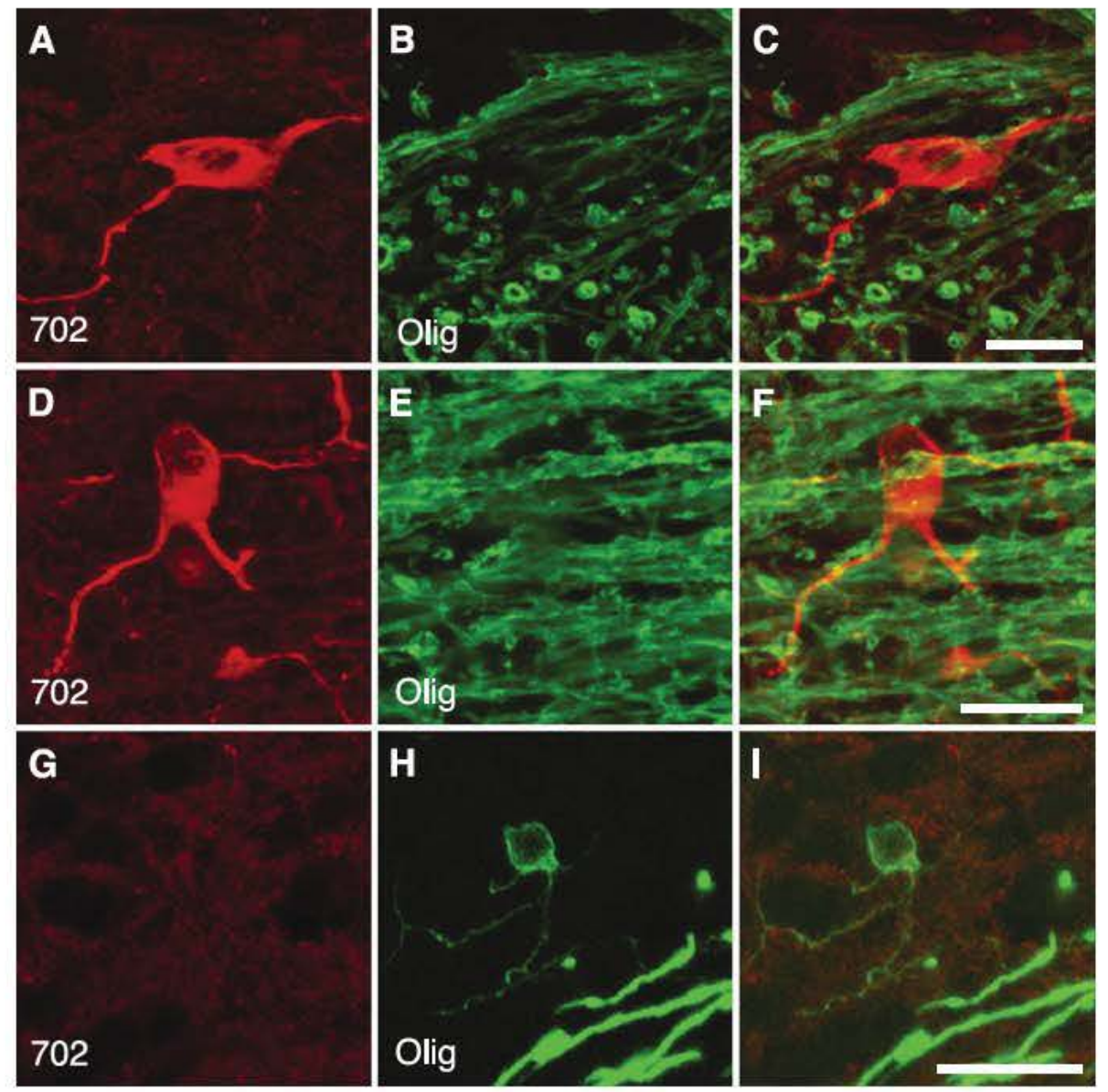

Fig. 7. Detection of Nogo-A/RTN4-A protein in neurons. Confocal microscopic analysis was performed on PFA-fixed sections of Xenopus spinal cord (A C) and brain (D I). The cellular staining observed with AS702 (A, D) does not colocalise with the myelin marker Olig (B, E), indicating neuronal expression of Nogo-A/RTN4-A. With this fixation protocol, no staining of oligodendrocyte cell bodies (identified by Olig, H) was observed with AS702 (G). Superpositions of the two stainings are shown in C, F and I, respectively. Scale bar is $20 \mu \mathrm{m}$. 
drocytes isolated from the spinal cord (Fig. 6A) and optic tectum (Fig. 6C), respectively. After permeabilisation, oligodendrocytes from both tissues were strongly positive for Nogo A/RTN4 A in particular, the radially organised cytoplasm (Figs. 6A and C). Antibody specificity for Xenopus Nogo A/RTN4 A was verified in control experiments. AS706 no longer stained oligodendrocytes from the spinal cord (Fig. 6B) and tectum opticum (Fig. 6D) after preincubation with the recombinant protein used for its generation.

The staining pattern with Xenopus Nogo A/RTN4 A antisera was strongly dependent on the fixation method. After formalde hyde fixation, Nogo A/RTN4 A was detected in specific cells and their processes in the spinal cord (Fig. 7A) and brain sections (Fig. 7D). These cells were not recognized by the oligodendrocyte marker Olig (Figs. 7B and E and superpositions in Figs. 7C and F) and probably represent neurons, as shown in the rat (Huber et al., 2002). Under these conditions, Nogo A/RTN4 A staining of white matter and oligodendrocyte cell bodies (identified by Olig, Fig. 7H) was lost (Fig. 7G).

These results demonstrate that Xenopus Nogo A/RTN4 A proteins are expressed in oligodendrocytes, CNS myelin and subpopulations of neurons. This pattern is comparable to that of the rat ortholog, which may indicate related functions.

\section{Discussion}

Here, we report the identification of nogo/rtn 4 genes in $X$. laevis and provide evidence for the expression of Nogo A homologous proteins. Inhibitory proteins like Nogo A, MAG and OMgp (Chen et al., 2000; McKerracher et al., 1994; Wang et al., 2002a) are suggested to impair axonal regeneration in the adult mammalian CNS. Because Xenopus spinal cord oligoden drocytes and CNS myelin also exert inhibitory functions in vitro (Lang et al., 1995), similar proteins are expected in this species. In contrast, CNS axons readily regenerate in the optic nerve and spinal cord of fish and urodeles (Clarke et al., 1988; Gaze, 1970). Anura, like X. laevis, take an intermediate position: retinal ganglion cell axons are capable of lifelong regeneration (Gaze, 1970) but spinal cord fiber tracts fail to regenerate after metamorphosis and myelination of axons (Beattie et al., 1990). Our present results show that Nogo A orthologs as candidate growth inhibitory factors exist in frogs.

We identified two independent $r$ tn 4 genes (rtn4.1 and rtn4.2) that result from the tetraploidization of the Xenopus genome. As in mammals, several mRNA transcripts are generated from rtn4.1 and rtn 4.2 either through alternative splicing $(\operatorname{rtn} 4 \mathrm{~A}$; $r \operatorname{tn} 4 \mathrm{~B})$ or probably alternative promoter usage $(\mathrm{rtn} 4 \mathrm{C} ; \mathrm{rtn} 4 \mathrm{~N})$. The sequen ces of Xenopus $\mathrm{rtn} 4 \mathrm{~A}, \mathrm{~B}$ and $\mathrm{C}$ are related to the three major transcripts of the mammalian nogo/rtn4 gene whereas Xenopus $\mathrm{rtn} 4 \mathrm{~N}$ is a newly identified short form that has not been identified in mammals (Oertle et al., 2003a).

The expression of the main Xenopus Nogo A/RTN4 A isoforms (RTN4 A1) of both $r \operatorname{tn} 4.1$ and $r$ tn 4.2 genes is mostly restricted to CNS regions and to the heart as shown by RT PCR and Western blotting. This pattern is comparable to Nogo A expression in mammals as summarised in Table 1. Immunostainings with antisera raised against Xenopus Nogo A/RTN4 A on tissue sections are also consistent with the Nogo A distribution in rodents (Huber et al., 2002; Josephson et al., 2001; Wang et al., 2002b). Xenopus Nogo A/ RTN4 A is expressed in myelinated tracts of the spinal cord and hindbrain, that is, regions labeled by the myelin marker Olig (Steen et al., 1989). This distribution corresponds to the outcome of earlier functional assays demonstrating the presence of axon growth inhibitory activity in myelin and oligodendrocytes of the Xenopus spinal cord (Lang et al., 1995). Xenopus Nogo A/RTN4 A specific antisera also labeled isolated oligodendrocytes in culture. Thus, the distribution of Xenopus Nogo A/RTN4 A in oligodendrocytes and CNS myelin is consistent with its postulated role as an inhibitor of axon regeneration.

However, Nogo A/RTN4 A1 is also detected in myelin and oligodendrocytes of the optic nerve and the forebrain. Moreover, RTN4 A1 proteins are already expressed early in development (data not shown) when oligodendrocytes or neurons are not yet present. An early presence of Nogo A has also been described in a variety of foetal rat tissues (Huber et al., 2002; Josephson et al., 2001). This early appearance and the intracellular localization of Nogo A/RTN4 A suggest further, yet unidentified, functions that are not related to axonal growth inhibition.

The expression pattern revealed by RTN4 A specific antisera differs from the weak and more restricted staining observed with $\mathrm{mAb}$ IN 1. One speculation is that IN 1 recognizes a Nogo A modification or conformational epitope relevant for surface expo sure and function. This would explain why only mAb IN 1 is able to discriminate between spinal cord and forebrain oligodendrocytes and to partially neutralize the inhibitory activity of Xenopus spinal cord and hindbrain myelin (Lang et al., 1995). This implies that changes in subcellular distribution (intracellular vs. surface) or posttranslational modifications are essential for the acquisition of the suggested inhibitory activity of Nogo A in the adult CNS in vivo (Oertle et al., 2003d). Future analyses of the inhibition process and the elucidation of the respective roles of Xenopus RTN4.1 A and RTN4.2 A will be required to address those unresolved problems. Moreover, relevant axonal receptors remain to be identified. The contribution of other inhibitory myelin components such as MAG, OMgp and proteoglycans (Morgenstern et al., 2002) needs to be considered and the potential role of Nogo 66 in the regeneration or inhibition scenario (GrandPré et al., 2000) has to be clarified in frogs.

Apart from myelinated regions, Xenopus Nogo A/RTN4 A antisera stain forebrain and midbrain regions that are not detected by myelin markers. These are seemingly neurons and neuropil, which is consistent with the detection of mammalian Nogo A in neurons and neuronal processes (Huber et al., 2002; Josephson et al., 2001; Wang et al., 2002b). The putative neuron specific functions of Nogo A, which probably differ from the oligodendrocyte related inhibitory activity, remain to be explored.

Compared to the preferential expression of Nogo A/RTN4 A in the nervous system, the B isoforms are ubiquitously expressed with highest levels in nonneuronal tissues (Table 1). High level expres sion of the Nogo A splice form in a specific tissue seems to be paralleled by low levels of the B isoforms, as is observed in mammals (Oertle et al., 2003a). Besides the many similarities between Xenopus and mammalian Nogo A expression, differences exist. The A isoform is not detected in mammalian lung and kidney, but is present in these organs in Xenopus, and Nogo B in liver is only found in Xenopus (Table 1; Hunt et al., 2002b; Oertle and Schwab, 2003). In addition, more minor splice variants of Nogo A and B exist in Xenopus than in mammals, resulting from the alternative usage of two small exons located between the A/B specific exon and the large A specific exon (Fig. 1). The weak expression of these minor splice variants is comparable to the expression levels of the 
mammalian minor splice variants ( $\mathrm{rtn} 4 \mathrm{~B} 2, \mathrm{D}, \mathrm{E}, \mathrm{F}, \mathrm{G}, \mathrm{Aa}, \mathrm{Ab}$; Oertle et al., 2003a) and could indicate a modulatory or develop mentally regulated role as suggested for the human testis specific RTN4 E splice variant (Zhou et al., 2002).

As in mammals, Xenopus RTN4 C is enriched in the adult skeletal muscle (Table 1). The Xenopus rtn4.1 C isoform is also expressed in the liver, eye and kidney. In contrast, the rtn $4.2 \mathrm{C}$ paralog is hardly detectable except for the muscle. This could indicate that the putative Xenopus rtn $4.2 \mathrm{C}$ promoter is undergoing transcriptional silencing.

The rtn $4 \mathrm{~N}$ mRNAs have a similarly restricted expression pattern, both being enriched in the heart and muscle (Fig. 3; Table 1). An $\mathrm{N}$ specific exon has not been identified in mammals. In zebrafish, however, a homologous $\mathrm{rtn} 4 \mathrm{~N}$ is present, but no $\mathrm{rtn} 4 \mathrm{~A}$, $\mathrm{B}$ and $\mathrm{C}$ transcripts (Klinger et al., 2002). It can therefore be hypothesized that the $\mathrm{N}$ terminal sequences specific for $\mathrm{rtn} 4 \mathrm{~A} / \mathrm{B}$ and $\mathrm{rtn} 4 \mathrm{C}$ were newly acquired during the evolution of land vertebrates (Oertle et al., 2003b). Accordingly, amphibians (e.g., $X$. laevis) express the 'ancestral' rtn4 $\mathrm{N}$ (that is also found in fish) and the 'modern' rtn4 A, B and C forms present in 'higher' vertebrates. Xenopus is, so far, the evolutionary 'lowest' organism that has the exceptionally large Nogo A specific exon, which codes for the potent inhibitory region NiG $\Delta 20$ contained only in Nogo A (Oertle et al., 2003d). Hence, the Xenopus rtn4 genes might help to elucidate how Nogo A acquired its inhibitory function. Conversely, Xenopus expresses the 'ancient' isoform $\operatorname{rtn} 4 \mathrm{~N}$, allowing the exploration of 'old' $\mathrm{rtn} 4$ features that are relevant in fish and frogs.

The duplication of Xenopus nogo/rtn 4 was dated to approxi mately 30 MYA using the rate of silent nucleotide substitutions as a "molecular clock" (Hughes and Hughes, 1993). In general, genome duplication events increase the amount of genetic material, which is considered as a prerequisite for the development of new genes with new functions. Duplicated genes can adopt different fates: both are expressed and have similar functions, one copy accumulates muta tions and eventually turns into a nonfunctional pseudogene, or a series of nondeleterious aa altering mutations transforms one copy into a gene with a new function, as can be determined by a significantly faster evolutionary rate (Van de Peer et al., 2001). On the other hand, mutations in regulatory elements together with the conservation of coding regions can alter the spatiotemporal expres sion of two genes with comparable function. The respective Xen opus rtn 4 transcripts of both genes display similar expression patterns, suggesting that the promotor regions responsible for the transcriptional regulation of these isoforms did not undergo major functional changes after the duplication event. Thus, these genes appear to be redundant rather than complementary, which is also supported by our observation that neither of the two copies in comparison to the human ortholog evolved faster. However, both rtn4 genes accumulated more aa altering mutations than one might expect for an evolutionary time of approximately 30 MYA (Hughes and Hughes, 1993), which suggests the commencement of a potential diversification and of functional changes of both copies.

The present identification of nogo/rtn 4 in X. laevis and the analysis of the expression pattern of Nogo A/RTN4 provide the first step towards understanding the evolution of myelin associated proteins with axonal growth inhibiting effects. Future experiments will determine the contribution of Nogo 66 and the Nogo A specific region to the growth inhibitory properties of Xenopus spinal cord myelin. A possible approach to tackle this issue is the generation of function blocking antibodies binding to the oligodendrocyte sur face. In addition, this study is a first entry point for functional analysis of Nogo A during development and axonal growth.

The synthesis of ancient and modern features within the nogo/ rtn 4 gene locus of Xenopus as well as the indications for a beginning diversification of the duplicated paralogs is relevant for the comprehension of gene evolutionary processes, particularly in the transition to land vertebrates.

\section{Experimental methods}

Animals

All animals were kept at the animal research facility of the University of Konstanz in compliance with animal welfare legis lation. X. laevis were anesthetized and killed in a $0.03 \%$ solution of MS222 (Sigma Aldrich, Seelze, Germany) for tissue preparation. Chinchilla bastard rabbits were used for immunization and RTN4 antibody generation.

\section{Nomenclature of Xenopus nogo/rtn4 transcripts}

Xenopus nogo transcripts were named according to the nomen clature guidelines for reticulon genes (Oertle et al., 2003b). In brief, $r t h$ serves as a gene symbol for chordate reticulons. Para logous rtn sequences are arbitrarily numbered with nogo being rtn4. Reticulon genes that have been duplicated within the same species share the same symbol and differ by an additional number (e.g., rtn4.1 and rtn4.2). To distinguish $r t n$ genes of various species, a prefix according to the identification code proposed by SWISS PROT is used (e.g., (XENLA)rtn4.1). Alternative tran scripts from different promoters receive a new letter (e.g., (XEN LA)rtn4.1 A, (XENLA)rtn4.1 C), while alternatively spliced transcripts derived from the same promoter have the same letter but are distinguished by the consecutive numbering (e.g., (XEN LA)rn4.1 A1, (XENLA)rnn4.1 A2). For historical reasons, rtn4 A and $\operatorname{rn} 4 \mathrm{~B}$ do not comply with this rule (Chen et al., 2000; GrandPré et al., 2000; Prinjha et al., 2000).

\section{Cloning with degenerate primers}

Total RNA was isolated from $X$. laevis embryos older than stage 50 (Trizol; Wak Chemie, Bad Homburg, Germany) and reverse transcribed following the manufacturer' $\mathrm{s}$ instructions (Ready to Go T primed first strand kit, Amersham Biosciences, Freiburg, Germany). Conserved sequence motifs of the nogo A cDNA of rat, human and chicken were used to design degenerate primers (Nogo A RN/se1: 5' CA[AG] GA[AG] AC[AGCT] GA[AG] GC[AGCT] CC[AGCT] TA[CT] AT 3', Nogo A RN/as2: AC[AG] TA[AGCT] GT[AG] AA[AGCT] ACC CAC AT). Using standard PCR, two different partial cDNA clones (1.2 kb) coding for two Xenopus rtn 4 genes were amplified. Both clones contain nogo A specific sequences (837 bp for (XENLA)rtn4.1 and 849 bp for (XEN LA)rtn4.2) and parts of the reticulon homology domain (381 and $384 \mathrm{bp}$, respectively).

\section{$5^{\prime}$ and $3^{\prime}$ rapid amplification of cDNA ends (RACE) and full length cloning}

The SMART RACE cDNA amplification kit (BD Clontech, Heidelberg, Germany) was used to determine the $5^{\prime}$ and $3^{\prime}$ 
sequences including the putative start methionines and $3^{\prime}$ non coding regions for both the (XENLA)rtn4.1 and (XENLA)rtn4.2, transcripts. Total RNA (1.3 $\mu \mathrm{g} /$ reaction) served as template for the synthesis of first strand $5^{\prime}$ Ready cDNA using $5^{\prime}$ CDS and SMART II oligonucleotides and $3^{\prime}$ Ready cDNA using $3^{\prime} \mathrm{CDS}$ primer, according to the manufacturer' $\mathrm{s}$ protocol.

The rtn 4 A specific primer $5^{\prime}$ RACE GSP XL (5' AGA ATC TGG TGA GCT TTC ATC GGA GGG C 3'; bp 17971824 of (XENLA)rtn4.1 A3 and bp 17641791 of (XENLA)rtn4.2 A3, respectively) was used to amplify $5^{\prime} \mathrm{cDNA}$ ends of both $\operatorname{rtn} 4 \mathrm{~A}$ transcripts. To clone additional $\mathrm{rtn} 4$ isoforms (B, C and $\mathrm{N})$, a $5^{\prime}$ RACE primer in the reticulon homology domain (RHD) was used (5'RACE GSP XL 3: 5' CTG GCA CCG CCA GGT TGG ACT CCA AGA TGG 3'; bp 27202749 of (XENLA)rtn4.1 A3 and bp 26872716 of (XENLA)rtn4.2 A3, respectively).

The $3^{\prime}$ ends including UTRs were completed using primer $3^{\prime}$ RACE GSP XL (5' CCC CCT TCG AAG GAA GAT GAT GGT TCC 3'; bp 24222448 of (XENLA)rtn4.1 A3) and 3'RACE GSP XL2 (5' AAC CCG AAC CCC CTT CAA AGA AAG ATG AGG 3'; bp 23752404 of (XENLA)rtn4.2 A3), respectively. All RACE reactions were performed as described in the manufacturer's protocol, and PCR products were directly cloned into pCRII TOPO vector (Invitrogen, Karlsruhe, Germany).

Full length clones of the alternative nogo transcripts ( $r \operatorname{tn} 4 \mathrm{~A}$, $\mathrm{B}, \mathrm{C}$ and $\mathrm{N}$ ) were obtained for both $X$. laevis nogo genes using primers located at the $5^{\prime}$ and $3^{\prime}$ ends of the various transcripts. (XENLA)rtn4.1 and (XENLA)rtn4.2 specific dbESTs were iden tified as described elsewhere (Oertle et al., 2003b). Sequences were deposited in GenBank (GenBank accession numbers, AY316183 AY316197).

\section{DNA sequencing and sequence analysis}

Plasmid DNA of RACE and full length clones was prepared using the QIAprep ${ }^{\circledR} 8$ Miniprep Kit (Qiagen, Hilden, Germany). Both DNA strands were sequenced using the Abi Prism ${ }^{\circledR}$ BigDye $^{\mathrm{TM}}$ Terminator Cycle Sequencing Kit (Applied Biosystems, Darmstadt, Germany). Sequencing products were analysed on an AbiPrism 3100 Genetic Analyser (Applied Biosystems). Single sequences were assembled using the Lasergene software package (GATC Biotech, Konstanz, Germany). Molecular evolutionary analyses were conducted using MEGA version 2.1 (Kumar et al., 2001). In brief, sequences were aligned at the amino acid level by the CLUSTALW program and gaps were pair wise deleted. Numb ers of synonymous nucleotide substitutions per synonymous site $\left(d_{\mathrm{S}}\right)$ and nonsynonymous substitutions per nonsynonymous site $\left(d_{\mathrm{N}}\right)$ were estimated (Nei and Gojobori, 1986) for both (XEN LA)rtn4 sequences and the human ortholog.

\section{$R T P C R$}

Various tissues (spinal cord, tectum opticum, forebrain, retina, sciatic nerve, heart, muscle, lung, kidney, liver) were dissected from adult $X$. laevis and used for preparation of total RNA with QIAshredders and the RNeasy Mini Prep Kit (Qiagen) following the manufacturer's instructions ( $<30 \mathrm{mg}$ tissue/column). Muscle tissue was additionally subjected to proteinase $\mathrm{K}$ digestion (200 $\mu \mathrm{g} / 30 \mathrm{mg}$ tissue).

First strand cDNA was synthesized with the Superscript First Strand Synthesis System for RT PCR (Invitrogen). Up to $5 \mu \mathrm{g}$ of total RNA was reverse transcribed under standard conditions with
$0.5 \mu \mathrm{g}$ oligo $(\mathrm{dT})_{12-18}$ primer. Zero transcriptions (without $\mathrm{Su}$ perscript II in the reaction) were performed in parallel to control for genomic DNA contaminations in subsequent PCRs. Amount and quality of the different cDNA samples were evaluated comparing the expression level of the housekeeping gene clathrin (primers: 5' GAC AGT GCC ATC ATG AAT CC $3^{\prime}$ and $5^{\prime}$ TTT GTG CTT CTG GAG GAA AGA A 3'; 28 cycles, annealing $50^{\circ} \mathrm{C}$, elongation $60 \mathrm{~s}$ ). Using this PCR as an internal reverence, the concentration of the cDNAs was adjusted to comparable levels.

A standard $25 \mu \mathrm{l}$ PCR reaction contained $2.5 \mu \mathrm{l}$ of $10 \times$ reaction buffer $(500 \mathrm{mM} \mathrm{NaCl} / 15 \mathrm{mM} \mathrm{MgCl} / 100 \mathrm{mM}$ Tris $\mathrm{Cl}$, pH 9.0; Amersham Biosciences), $0.3 \mu \mathrm{l}$ dNTP mix (10 mM each), $1 \mu \mathrm{l}$ of first strand cDNA, $0.75 \mathrm{U}$ Taq DNA polymerase (Amersham Biosciences) and 50 pmol of the appropriate sense and antisense primers (see Supplementary Table 1A for sequence information and arrows in Fig. 1 for primer positions). PCR conditions for rtn4.1 A and rtn4.2 A (primers III + IV and VIII + IX, respectively) were $94^{\circ} \mathrm{C}$ for $30 \mathrm{~s}, 76^{\circ} \mathrm{C}$ for $30 \mathrm{~s}$ and $72^{\circ} \mathrm{C}$ for $75 \mathrm{~s}$ ( 30 cycles). Different splice variants of $\mathrm{rtn} 4.1 \mathrm{~A}$ and $\mathrm{rtn} 4.2 \mathrm{~A}(1,2$ and 3$)$ were amplified using the Expand Long Template PCR System (Roche Diagnostics, Mannheim, Germany) because PCR with Taq polymerase failed in this GC rich sequence. This 'sensitive' PCR was performed with primers I + II and VI + VII, respectively, twice the amount of cDNA $(2 \mu \mathrm{l})$ and the following cycling parameters: $92^{\circ} \mathrm{C}$ for $10 \mathrm{~s}, 66^{\circ} \mathrm{C}$ for $10 \mathrm{~s}, 68^{\circ} \mathrm{C}$ for $40 \mathrm{~s}\left(24\right.$ cycles), $92^{\circ} \mathrm{C}$ for $10 \mathrm{~s}, 66^{\circ} \mathrm{C}$ for $10 \mathrm{~s}, 68^{\circ} \mathrm{C}$ for $40+1 \mathrm{~s} /$ cycle (15 cycles).

Rtn4.1 B and $\operatorname{rtn} 4.2 \mathrm{~B}$ splice variants were amplified using primer combinations I $+\mathrm{V}$ and $\mathrm{VI}+\mathrm{X}$, respectively $\left(92^{\circ} \mathrm{C}\right.$ for $10 \mathrm{~s}$, $63^{\circ} \mathrm{C}$ for $10 \mathrm{~s}, 68^{\circ} \mathrm{C}$ for $23 \mathrm{~s}(20$ cycles $), 92^{\circ} \mathrm{C}$ for $10 \mathrm{~s}, 63^{\circ} \mathrm{C}$ for $10 \mathrm{~s}, 68^{\circ} \mathrm{C}$ for $23+1 \mathrm{~s} /$ cycle $(15$ cycles $\left.)\right)$. The short elongation time excluded amplification of A splice variants in the same PCR reaction. All alternative splice products were subcloned into pCRII TOPO vector and confirmed by sequencing.

Conditions for rtn4.1 C and rtn4.2 C (standard PCR; primers $\mathrm{XI}+\mathrm{XII}$ and XI $+\mathrm{XV}$, respectively) were $94^{\circ} \mathrm{C}$ for $20 \mathrm{~s}, 63^{\circ} \mathrm{C}$ for $15 \mathrm{~s}$ and $72^{\circ} \mathrm{C}$ for $40 \mathrm{~s}$ (35 cycles). Rtn $4.1 \mathrm{~N}$ was amplified using primer combination XIII + XII and standard PCR $\left(94^{\circ} \mathrm{C}\right.$ for $20 \mathrm{~s}$, $65^{\circ} \mathrm{C}$ for $15 \mathrm{~s}$ and $72^{\circ} \mathrm{C}$ for $45 \mathrm{~s} ; 35$ cycles). For rtn $4.2 \mathrm{~N}$ detection, the AccuPrime System together with primers XIV + XV was applied $\left(94^{\circ} \mathrm{C}\right.$ for $20 \mathrm{~s}, 63^{\circ} \mathrm{C}$ for $15 \mathrm{~s}$ and $68^{\circ} \mathrm{C}$ for $45 \mathrm{~s} ; 35$ cycles $)$.

For each primer combination, positive and negative control PCRs on $\operatorname{rtn} 4.1$ and 2 plasmid DNA were included to prove specificity for one of the two genes. All PCRs were performed at least in duplicate, analysed on $1.5 \%(\mathrm{w} / \mathrm{v})$ agarose gels and documented with a Molecular Imager FX (Bio Rad, München, Germany).

\section{Oligodendrocyte cultures}

Tectum opticum and spinal cord of anesthetized postmetamor phic froglets were dissected in L 15 medium (Invitrogen) and the meninges and peripheral nerve roots were removed. The tissue was chopped with a McIlwain tissue chopper (Vibratome, St. Louis MO, USA) and the fragments were rinsed twice in L 15 containing $10 \%(\mathrm{v} / \mathrm{v})$ fetal calf serum (FCS, Invitrogen). After centrifugation, the tissue was resuspended in 80\% (v/v) DMEM/Ham's F 12 1:1, containing $10 \%(\mathrm{v} / \mathrm{v})$ FCS, $0.4 \%(\mathrm{w} / \mathrm{v})$ methyl cellulose, $15 \mathrm{mM}$ HEPES, $3.5 \mathrm{mg} / \mathrm{ml}$ glucose, $0.1 \mathrm{mg} / \mathrm{ml}$ glutamine, $5 \times 10^{-3} \mathrm{mg} / \mathrm{ml}$ insuline, $0.1 \mathrm{mM}$ putrescine, $2 \times 10^{-5} \mathrm{mM}$ progesterone, $3 \times 10^{-5}$ $\mathrm{mM}$ sodium selenite (all Sigma Aldrich) and $0.05 \mathrm{mg} / \mathrm{ml}$ genta 
micine (Invitrogen) and plated on polylysine/laminin coated cover slips (Bastmeyer et al., 1989). Cultures were further treated as described by Lang et al. (1995). Differentiated oligodendrocytes were obtained by adding $10 \mu \mathrm{M}$ Forskolin (Biomol GmbH, Hamburg, Germany) to the culture medium.

\section{Antibodies}

For the generation of antisera AS702 and AS706, two different regions of the (XENLA)rtn4.1 A sequence (for details see Fig. 1) were cloned into pTrcHis expression vector (Invitrogen) and recombinantly expressed in Top $10 \mathrm{~F}^{\prime} E$. coli after IPTG induction. His tagged proteins were purified under denaturing conditions on $\mathrm{Ni}^{+}$NTA spin columns (Qiagen) according to the manufacturer. Eluted protein $(500 \mu \mathrm{l})$ was mixed with adjuvant $(500 \mu \mathrm{l} \mathrm{MPL}+$ TDM + CWS, No. M6661, Sigma Aldrich) and injected into rabbits every second week for five times. IgG fractions were isolated via a Protein A affinity chromatography (Amersham Biosciences) according to standard protocols. Specificity of AS702 and AS706 was increased by pre absorption against general E. coli and unrelated His tagged proteins. Proteins 833 (RTN4.1) and 834 (RTN4.2) were similarly expressed and purified to test specificity of AS702 and AS706.

Antibodies were used as follows: AS702 and AS706 against Xenopus Nogo A/RTN4 A at 1:1000 for immunohistochemistry on tissue sections and at 1:10,000 for western blotting; AS 472 against rat Nogo A (aa 623 640, affinity purified) at 1:10,000; monoclonal antibody $(\mathrm{mAb})$ Olig hybridoma supernatant against oligodendro cytes/myelin (Steen et al., 1989) at 1:2 and mAb IN 1 hybridoma supernatant (Caroni and Schwab, 1988a) undiluted. Secondary antibodies were Cy3 conjugated donkey anti rabbit IgG; HRP conjugated goat anti rabbit IgG (Jackson ImmunoResearch West Grove PA, USA), Alexa 488 conjugated goat anti mouse IgG (Molecular Probes, Eugene OR, USA) and biotin conjugated goat anti mouse IgM ( $\mu$ chain specific; Vector Laboratories, Burlingame CA, USA).

\section{Immunohistochemistry}

For AS702, AS706 and IN 1 staining, isolated brains, spinal cords and retinae with optic nerves of stage $66 \mathrm{X}$. laevis were embedded in TissueTek (Sakura Finetek, Zoeterwoude, The Neth erlands) and frozen in liquid nitrogen. Sections $(12 \mu \mathrm{m})$ were cut on a cryostat (Leica, Bensheim, Germany), collected on SuperFrost Plus glass slides (Menzel Glaser, Freiburg, Germany), fixed in Clark's solution $(95 \%(\mathrm{v} / \mathrm{v})$ ethanol $/ 5 \%(\mathrm{v} / \mathrm{v})$ acetic acid; $25 \mathrm{~min}$ at $\left.4{ }^{\circ} \mathrm{C}\right)$, rehydrated in $70 \%(\mathrm{v} / \mathrm{v})$ ethanol $\left(10 \mathrm{~min}\right.$ at $\left.4{ }^{\circ} \mathrm{C}\right)$ and rinsed in PBS. Alternatively, tissues were fixed in $2 \%(\mathrm{w} / \mathrm{v})$ PFA (overnight at $4{ }^{\circ} \mathrm{C}$ ), washed in PBS, transferred into a $20 \%(\mathrm{w} / \mathrm{v})$ sucrose solution (overnight at $4{ }^{\circ} \mathrm{C}$ ) and embedded in TissueTek before sectioning. PFA fixed sections were stained with AS702, AS706 or the myelin marker Olig. For Olig staining, $0.1 \%(\mathrm{v} / \mathrm{v})$ Triton X 100 (Sigma Aldrich) was added to the antibody solution.

Sections were incubated with primary antibodies (overnight at $4^{\circ} \mathrm{C}$ ), rinsed in PBS, incubated with appropriate secondary anti bodies (either $\mathrm{Cy} 3$ conjugated or biotinylated antibodies together with $\mathrm{ABC}$ and $\mathrm{DAB}$ kits (Vector Laboratories; $1 \mathrm{~h}$ at RT), rinsed and coverslipped with Mowiol (Merck Biosciences, Schwalbach, Germany) containing n propyl gallate (Sigma Aldrich).

Cultured oligodendrocytes were fixed in methanol $\left(-20^{\circ} \mathrm{C}, 5\right.$ min), rinsed in PBS, incubated with AS706 overnight at $4{ }^{\circ} \mathrm{C}$, rinsed in PBS, incubated with Cy3 conjugated secondary antibody plus 50 ng/ml DAPI (4',6' Diamidino 2 Phenylindole; Sigma Aldrich) for 1 $\mathrm{h}$ at RT, rinsed and coverslipped with Mowiol. For blocking experi ments, AS706 was preincubated with $0.45 \mathrm{mg} / \mathrm{ml} \mathrm{recombinant}$ protein 706 for $1 \mathrm{~h}$ at $4^{\circ} \mathrm{C}$ before staining.

\section{Gel electrophoresis and immunoblotting}

$X$. laevis tissues were homogenized, separated on NewPAGE ${ }^{\circledR}$ Novex ${ }^{\circledR} 3 \quad 8 \%$ high resolution gradient tris acetate gels (Invitro gen) and transferred to Hybond C Super nitrocellulose membranes (Amersham Biosciences) in a tank blot apparatus. For immunode tection, the membranes were incubated in blocking solution $(3 \%$ (w/v) milk powder/0.05\% (v/v) Tween 20/350 mM NaCl in PBS) at RT for at least $30 \mathrm{~min}$. Primary antibody was added overnight at $4^{\circ} \mathrm{C}$. After three washes for $15 \mathrm{~min}$ each with washing buffer $(350$ $\mathrm{mM} \mathrm{NaCl} / 0.05 \%(\mathrm{v} / \mathrm{v})$ Tween 20 in PBS), the membranes were incubated with HRP coupled secondary antibody for $12 \mathrm{~h}$ at RT. After three washes (10 min each), the blots were developed using the ECL Detection Kit (Amersham Biosciences) or SuperSignal West Pico (Pierce, Bonn, Germany) and exposed to X ray films (Hyperfilm ECL; Amersham Biosciences).

\section{Acknowledgments}

C.A.O.S. was supported by the Deutsche Forschungsgemein schaft (DFG), M.K. by the "Stiftung der Deutschen Wirtschaft für Qualifizierung und Kooperation e.V. (sdw)" T.O. and M.E.S. by the Swiss National Science Foundation (Grant No. 31 63633) and by the NCCR on Neural Plasticity and Repair. The hybridoma supernatant of the monoclonal antibody Olig (developed by M. Constantine Paton) was obtained from the Developmental Studies Hybridoma Bank developed under auspices of the NICHD and maintained by the University of Iowa, Department of Biological Science. Iowa City, IA 52242. We thank U. Binkle for technical assistance and J. Taylor for critical reading of the manuscript.

\section{References}

Bastmeyer, M., Beckmann, M., Nona, S.M., Cronly-Dillon, J.R., Stuermer, C.A., 1989. Identification of astrocyte- and oligodendrocyte-like cells of goldfish optic nerves in culture. Neurosci. Lett. 101, 127132.

Beattie, M.S., Bresnahan, J.C., Lopate, G., 1990. Metamorphosis alters the response to spinal cord transection in Xenopus laevis frogs. J. Neurobiol. 21, 11081122.

Caroni, P., Schwab, M.E., 1988a. Antibody against myelin-associated inhibitor of neurite growth neutralizes nonpermissive substrate properties of CNS white matter. Neuron 1, 8596.

Caroni, P., Schwab, M.E., 1988b. Two membrane protein fractions from rat central myelin with inhibitory properties for neurite growth and fibroblast spreading. J. Cell Biol. 106, 12811288.

Chen, M.S., Huber, A.B., van der Haar, M.E., Frank, M., Schnell, L., Spillmann, A.A., Christ, F., Schwab, M.E., 2000. Nogo-A is a myelin-associated neurite outgrowth inhibitor and an antigen for monoclonal antibody IN-1. Nature 403, 434439.

Clarke, J.D., Alexander, R., Holder, N., 1988. Regeneration of descending axons in the spinal cord of the axolotl. Neurosci. Lett. 89, 16.

Forehand, C.J., Farel, P.B., 1982. Anatomical and behavioral recovery from the effects of spinal cord transection: dependence on metamorphosis in anuran larvae. J. Neurosci. 2, 652654 . 
Gaze, R.M., 1970. The Formation of Nerve Connections. Academic Press, New York.

GrandPré, T., Nakamura, F., Vartanian, T., Strittmatter, S.M., 2000. Identification of the Nogo inhibitor of axon regeneration as a Reticulon protein. Nature 403, 439444.

Huber, A.B., Weinmann, O., Brosamle, C., Oertle, T., Schwab, M.E., 2002. Patterns of Nogo mRNA and protein expression in the developing and adult rat and after CNS lesions. J. Neurosci. 22, 35533567.

Hughes, M.K., Hughes, A.L., 1993. Evolution of duplicate genes in a tetraploid animal, Xenopus laevis. Mol. Biol. Evol. 10, 13601369.

Hunt, D., Coffin, R.S., Anderson, P.N., 2002a. The Nogo receptor, its ligands and axonal regeneration in the spinal cord; a review. J. Neurocytol. 31, 93120 .

Hunt, D., Mason, M.R., Campbell, G., Coffin, R., Anderson, P.N., 2002 b. Nogo receptor mRNA expression in intact and regenerating CNS neurons. Mol. Cell. Neurosci. 20, 537552.

Josephson, A., Widenfalk, J., Widmer, H.W., Olson, L., Spenger, C., 2001. NOGO mRNA expression in adult and fetal human and rat nervous tissue and in weight drop injury. Exp. Neurol. 169, 319328.

Klinger, M., Diekmann, H., Haenisch, C., Oertle, T., Schwab, M.E., Stuermer, C.A.O., 2002. Cloning and characterization of zebrafish reticulon genes including nogo/RTN-4. Soc. Neurosci. Abst. 28 (Programm No. 333.314)

Kozak, M., 1996. Interpreting cDNA sequences: some insights from studies on translation. Mamm. Genome 7, 563574

Kumar, S., Tamura, K., Jakobsen, I.B., Nei, M., 2001. MEGA2: Molecular Evolutionary Genetics Analysis Software. Tempe, Arizona, USA.

Lang, D.M., Stuermer, C.A., 1996. Adaptive plasticity of Xenopus glial cells in vitro and after CNS fiber tract lesions in vivo. Glia 18,92 106.

Lang, D.M., Rubin, B.P., Schwab, M.E., Stuermer, C.A., 1995. CNS myelin and oligodendrocytes of the Xenopus spinal cord but not optic nerve are nonpermissive for axon growth. J. Neurosci. 15, 99109.

Li, W.H., Gouy, M., Sharp, P.M., O’Huigin, C., Yang, Y.W., 1990. Molecular phylogeny of Rodentia, Lagomorpha, Primates, Artiodactyla, and Carnivora and molecular clocks. Proc. Natl. Acad. Sci. U. S. A. 87, 67036707.

McKerracher, L., David, S., Jackson, D.L., Kottis, V., Dunn, R.J., Braun, P.E., 1994. Identification of myelin-associated glycoprotein as a major myelin-derived inhibitor of neurite growth. Neuron 13, 805811.

Morgenstern, D.A., Asher, R.A., Fawcett, J.W., 2002. Chondroitin sulphate proteoglycans in the CNS injury response. Prog. Brain Res. 137, 313332.

Nei, M., Gojobori, T., 1986. Simple methods for estimating the numbers of synonymous and nonsynonymous nucleotide substitutions. Mol. Biol. Evol. 3, 418426.

Oertle, T., Schwab, M.E., 2003. Nogo and its paRTNers. Trends Cell Biol. 13, 187194.

Oertle, T., Huber, C., van der Putten, H., Schwab, M.E., 2003a. Genomic structure and functional characterisation of the promoters of human and mouse nogo/rtn4. J. Mol. Biol. 325, 299323.

Oertle, T., Klinger, M., Stuermer, C.A., Schwab, M.E., 2003b. A reticular rhapsody: phylogenic evolution and nomenclature of the RTN/Nogo gene family. FASEB J. 17, 12381247.

Oertle, T., Merkler, D., Schwab, M.E., 2003c. Do cancer cells die because of Nogo-B? Oncogene 22, 13901399.

Oertle, T., van der Haar, M.E., Bandtlow, C.E., Robeva, A., Burfeind, P., Buss, A., Huber, A.B., Simonen, M., Schnell, L., Brosamle, C., Kaupmann, K., Vallon, R., Schwab, M.E., 2003d. Nogo-A inhibits neurite outgrowth and cell spreading with three discrete regions. J. Neurosci. 23, 53935406 .

Prinjha, R., Moore, S.E., Vinson, M., Blake, S., Morrow, R., Christie, G., Michalovich, D., Simmons, D.L., Walsh, F.S., 2000. Inhibitor of neurite outgrowth in humans. Nature 403, 383384.

Spillmann, A.A., Bandtlow, C.E., Lottspeich, F., Keller, F., Schwab, M.E., 1998. Identification and characterization of a bovine neurite growth inhibitor (bNI-220). J. Biol. Chem. 273, 1928319293.

Steen, P., Kalghatgi, L., Constantine-Paton, M., 1989. Monoclonal antibody markers for amphibian oligodendrocytes and neurons. J. Comp. Neurol. 289, 467480.

Van de Peer, Y., Taylor, J.S., Braasch, I., Meyer, A., 2001. The ghost of selection past: rates of evolution and functional divergence of anciently duplicated genes. J. Mol. Evol. 53, 436446.

van de Velde, H.J., Roebroek, A.J., Senden, N.H., Ramaekers, F.C., Van de Ven, W.J., 1994. NSP-encoded reticulons, neuroendocrine proteins of a novel gene family associated with membranes of the endoplasmic reticulum. J. Cell Sci. 107, 24032416.

Wang, K.C., Koprivica, V., Kim, J.A., Sivasankaran, R., Guo, Y., Neve, R.L., He, Z., 2002a. Oligodendrocyte-myelin glycoprotein is a Nogo receptor ligand that inhibits neurite outgrowth. Nature 417, 941944.

Wang, X., Chun, S.J., Treloar, H., Vartanian, T., Greer, C.A., Strittmatter, S.M., 2002b. Localization of Nogo-A and Nogo-66 receptor proteins at sites of axon-myelin and synaptic contact. J. Neurosci. 22, 55055515 .

Zhou, Z.M., Sha, J.H., Li, J.M., Lin, M., Zhu, H., Zhou, Y.D., Wang, L.R., Wang, Y.Q., Zhou, K.Y., 2002. Expression of a novel reticulon-like gene in human testis. Reproduction 123, 227234. 